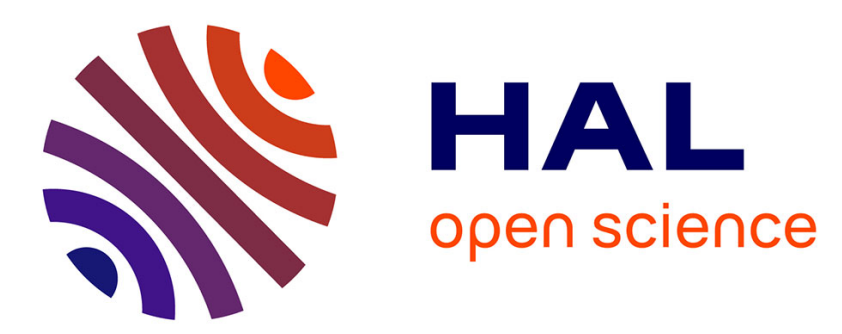

\title{
Local Structure of Catalytically Active Metal Clusters in Polymer Membranes
}

\author{
L. Troger, S. Nunes, M. Oehring, H. Hünnefeld, D. Fritsch
}

\section{To cite this version:}

L. Troger, S. Nunes, M. Oehring, H. Hünnefeld, D. Fritsch. Local Structure of Catalytically Active Metal Clusters in Polymer Membranes. Journal de Physique IV Proceedings, 1997, 7 (C2), pp.C2875-C2-877. 10.1051/.jp4:1997263 . jpa-00255346

\section{HAL Id: jpa-00255346 https://hal.science/jpa-00255346}

Submitted on 1 Jan 1997

HAL is a multi-disciplinary open access archive for the deposit and dissemination of scientific research documents, whether they are published or not. The documents may come from teaching and research institutions in France or abroad, or from public or private research centers.
L'archive ouverte pluridisciplinaire HAL, est destinée au dépôt et à la diffusion de documents scientifiques de niveau recherche, publiés ou non, émanant des établissements d'enseignement et de recherche français ou étrangers, des laboratoires publics ou privés. 


\title{
Local Structure of Catalytically Active Metal Clusters in Polymer Membranes
}

\author{
L. Tröger, S. Nunes*, M. Oehring**, H. Hünnefeld and D. Fritsch**
}

\author{
Hamburger Synchrotronstrahlungslabor (HASYLAB), Deutsches Elektronen-Synchrotron (DESY), \\ Notkestr. 85, 22603 Hamburg, Germany \\ * University of Campinas, Institute of Chemistry, 13083-970 Campinas, SP, Brazil \\ ** GKSS-Forschungszentrum Geesthacht GmbH, Max-Planck-Strasse, 21502 Geesthacht, Germany
}

\begin{abstract}
Metal clusters were stabilized in poly(amide imide) (PAI) polymers in high dispersion and large amounts of metal loading of typically $15 \mathrm{wt}-\%$. The loaded polymers are prepared as pore-free, mechanically stable membrane films. Pure Pdloaded and bimetallic $\mathrm{Pd} / \mathrm{Ag}, \mathrm{Pd} / \mathrm{Cu} \mathrm{PAI}$ films were investigated by means of $\mathrm{X}$-ray absorption spectroscopy (XAFS), X-ray diffraction (XRD) and transmission electron microscopy (TEM) to characterize the structure of the metal clusters in the protective polymer. The reduction of nitrous oxide by $\mathrm{Pd} / \mathrm{Ag}$-loaded membranes in the membrane mode is demonstrated. Cluster sizes are calculated from the measured XAFS coordination numbers by use of an onion model which describes the clusters as spherical metal cores with uniform oxide surface layers. All measurements consistently show a homogeneous distribution of metallic nanoclusters of size 1-6 nm with a smaller amount of larger aggregates in most of the films. Indications of metal alloying in bimetallic films are generally weak. The precise cluster size distribution critically depends on the solvents used as well as on other preparation parameters. In Pd/Cu-loaded membranes which are judged to be amorphous from the XRD spectra, XAFS clearly demonstrates a reaction of $\mathrm{Pd}$ with chlorine from $\mathrm{CuCl}_{2}$ precursors which may influence the Pd catalytic behavior. Reduction behavior of the metal nanoclusters at $300 \mathrm{~K}$ is linked by means of the onion model to microscopic quantities.
\end{abstract}

\section{INTRODUCTION}

Fundamental aspects as well as applications in catalysis are driving nanocluster research. Macroscopic amounts of nanoclusters need to be stabilized against further growth. Among several other methods this can be accomplished by generating the clusters inside polymers. Recently, metal clusters were stabilized in large amounts up to $30 \mathrm{wt}-\%$ in poly(amide imide) (PAI) polymer membranes which are mechanically stable and pore-free [1]. These membranes have been successfully tested for their catalytic activity [2]. In this communication, XAFS in comparison to XRD and TEM is used to investigate the structure and size distribution of the embedded clusters depending on preparation parameters and type of metal loading. An onion model is presented for the analysis of the XAFS data of Pd-nanoparticles which allows to determine average metal cluster core and oxide surface layer dimensions.

\section{EXPERIMENTAL}

Preparation of the metal-loaded polymers is performed as follows. Solved metal precursors (acetates, chlorides) are added to polymer solutions in tetrahydrofurane (THF) or N-methyl-pyrrolidone (NMP) to give a $10 \mathrm{wt} \%$ solution. After thorough mixing the solution is casted as a film on a glass plate and the solvent is evaporated overnight. After peeling-off from the plate the films are soaked in a methanol-sodiumborohydride solution for ten minutes. This fast reduction step forms nanosized clusters which are homogeneously distributed in the polymer matrix. Washing with methanol and drying in vacuum yields

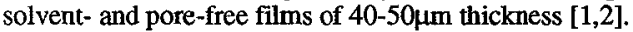

Gas permeation experiments with the metal-loaded membranes were performed at $30^{\circ} \mathrm{C}$ in the membrane mode using a self-built vacuum apparatus designed for time-lag measurements. XAFS experiments were performed at the Hamburger Synchrotronstrablungslabor (HASYLAB) at DESY, Germany. The spectra were taken at beamlines X1.1 and E4 of the storage ring DORIS III. These are equipped with Si(111) and Si(311) double-crystal monochromators and cover the photon energy range of 3-35keV. XAFS spectra of the K-edges of all metal atoms in each of the membranes were measured. Evaluation of the EXAFS data employed the programs FEFF, AUTOBK and FEFFIT from the University of Washington package [3,4]. XAFS Fourier transforms (FT) were fitted in distance space by one-, two- or three-shell fits using FEFF standards. For example, metallic Pd-Pd and oxidic Pd-O contributions which dominate most of the Pd K-edge FTs are fitted by two-shell fits with six variables: mean coordination numbers $N(P d-P \dot{d}), N(P d-O)$, mean interatomic distances $R(P d-P d), R(P d-O)$ and mean-square relative displacements $\sigma^{2}(P d-P d)$ and $\sigma^{2}(P d-O)$. Other parameters are fixed to the values of reference compounds. X-ray diffractograms were collected at a laboratory diffractometer using $\mathrm{Cu} \mathrm{K} \alpha$-radiation, TEM photographs were taken with a Zeiss CEM-902 microscope using only elastic electrons to improve the contrast.

\section{ONION MODEL}

Mean coordination numbers obtained from the XAFS fits carry important structural information of the clusters in two aspects. 
As an example, we consider monometallic, Pd-loaded membranes. First, $N(P d-P d)$ and $N(P d-O)$ are dependent on the fractions of oxidized and metallic $P d$ in the membrane. Secondly, in small clusters mean coordination numbers are reduced with decreasing cluster size due to the increasing surface-to-volume ratio of the clusters. Therefore, oxide and metal phase fractions as well as particle sizes can be determined by means of the following simple model (onion model). The metal particles in the membranes are assumed to be of spherical shape and to consist of a metal core and an oxidized surface layer, fully terminated by oxygen at the outer surface. It is further assumed that all metal clusters in the membrane have the same well-defined size of diameter $D$. Certainly, the actual clusters exhibit a size distribution so that $D$ expresses an effective, mean cluster size in which different cluster sizes are weighted according to their mass.

Pd atoms in the oxidized phase in good approximation do not have Pd nearest-neighbors and therefore only contribute to the first peak Pd-O in the FT. Accordingly, metallic Pd only contributes to the second FT peak Pd-Pd. The observed XAFS coordination numbers $N(P d-P d)$ and $n(P d-O)$ are therefore reduced from their bulk values of 4 and 12 , respectively, by the amount of which each of the phases is present in the membrane. In addition, small clusters have a significant number of surface atoms with reduced nearest-neighbor coordination. Dependent on the cluster size, mean coordination numbers are therefore further reduced. In the onion model, the experimentally observed mean XAFS coordination numbers $N(P d-P d)$ and $N(P d-O)$ are given by

$$
\begin{aligned}
& N(P d-P d)=12 \cdot f_{P d}(d) \cdot p\left(d, l_{o x}\right) \\
& N(P d-O)=4 \cdot f_{o}^{r i n g}\left(d, l_{o x}\right) \cdot\left[1-p\left(d, l_{o x}\right)\right]
\end{aligned}
$$

where $d$ denotes the diameter of the metal core of the cluster, $l_{o x}$ the thickness of the surface oxide layer, $D=d+2 l_{o x}$ is the full cluster diameter, $p\left(d, l_{o x}\right)$ the percentage of $\mathrm{Pd}$ atoms in the metallic phase in these clusters referred to the total amount of $\mathrm{Pd}$, and $f_{O}^{r i n g}\left(d, l_{o x}\right)$ and $f_{P d}(d)$ normalized mean coordination numbers taking into account surface effects in the oxide layer ring and the metal core, respectively. The latter functions vary between zero and one, $f_{P d}$ between zero in a single-atom-cluster and unity in the bulk. To obtain these functions, exact analytical formulae for mean XAFS coodination numbers in clusters of tetrahedral shape [5] were formulated in terms of the effective cluster diameter $d$ of a sphere of the same number of cluster atoms. This takes into consideration that the actual cluster shape is not perfectly spherical but of more open structure. For the normalized mean coordination number in the oxide surface layer $f_{o}^{r i n g}\left(d, l_{o x}\right)$ no exact formulae are available from the literature. Therefore, the results of Ref. [5] were transferred to this situation by applying a continuum description to the inverted problem of a hypothetical, isolated, spherical PdO-particle of diameter $d$ identical to the Pd metal core which is not terminated by oxygen at its outer surface [6]. By use of equations (1), from a pair of experimentally determined values $N(P d-P d)$ and $N(P d-O)$ the corresponding cluster diameter $D$ and the oxide layer thickness $l_{a x}$ are directly calculated. The above onion model extends approaches from the literature to determine particle sizes from XAFS coordination numbers to oxidized metal particles.

\section{RESULTS AND DISCUSSION}

To test the metal-loaded membranes for catalytic activity, a feed gas mixture of $\mathrm{N}_{2} \mathrm{O}$ and $\mathrm{H}_{2}$ was supplied to one side of the membrane. Feed gas and the gas which is permeating through the membrane are analysed by means of a mass spectrometer. Figure 1 shows the measured feed and permeate composition in steady-state condition as relative partial pressures monitored by mass spectrometry for a Pd/Ag(3:1)-loaded PAI membrane. The feed gas compositions applied in the left and right diagram of Fig. 1 correspond to $v / v$-ratios for $\mathrm{N}_{2} \mathrm{O} / \mathrm{H}_{2}$ of $1: 2$ and 1:1, respectively. The feed mass-spectrometer readings in Fig. 1 are given for comparison with the permeates. It is seen that for a feed gas composition $\mathrm{N}_{2} \mathrm{O} / \mathrm{H}_{2}=1: 2$ and more quantitatively for $\mathrm{N}_{2} \mathrm{O} / \mathrm{H}_{2}=1: 1$ the reaction of $\mathrm{N}_{2} \mathrm{O}$ and $\mathrm{H}_{2}$ to $\mathrm{N}_{2}$ and $\mathrm{H}_{2} \mathrm{O}$ is catalyzed by the Pd/Ag-loading of the membrane. The rate-limiting step in the catalytic reduction of $\mathrm{N}_{2} \mathrm{O}$ is the decomposition of the chemisorbed molecule on the metal (Pd) surface.

Figure $2 \mathrm{a}, \mathrm{b}$ show Pd K-edge XAFS spectra of the Pd-loaded membrane no. 2 (see Table 1), measured in air (solid lines). After $\mathrm{H}_{2}$-teduction (Fig. $2 \mathrm{c}$,d) the high frequency component corresponding to the Pd-Pd shell is increased on the expense of the lower frequency component which is due to a Pd-O contribution). Two-shell fits (dotted lines in Fig. 2) yield the coordination numbers $N(P d-P d), N(P d-O)$ listed in Table 1 (error $\approx 10 \%)$ from which the mean total diameter $D$ of the clusters and the thickness $l_{o x}$ of the surface oxide layer are obtained by the onion model. It is seen from Table 1 that reduction reduces the surface oxide layer thickness by a factor of two to the value of about a monolayer. The total diameter $D$ of the clusters, independently given by both measurements, remains unchanged. A similar reduction behavior is also seen for other membranes, like the $\mathrm{Pd} / \mathrm{Ag}(3: 1)$-loaded membrane no. 4 in Table 1 . However, the parameters $D, l_{o x}$ are mean quantities which average over
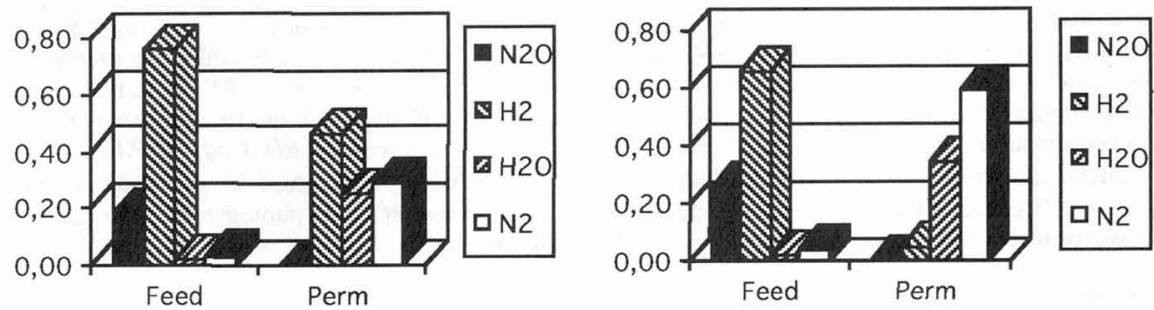

Figure 1: Reduction of $\mathrm{N}_{2} \mathrm{O}$ by a $\mathrm{Pd} / \mathrm{Ag}(3: 1)$-loaded membrane in the membrane mode for different feed gas composition. 

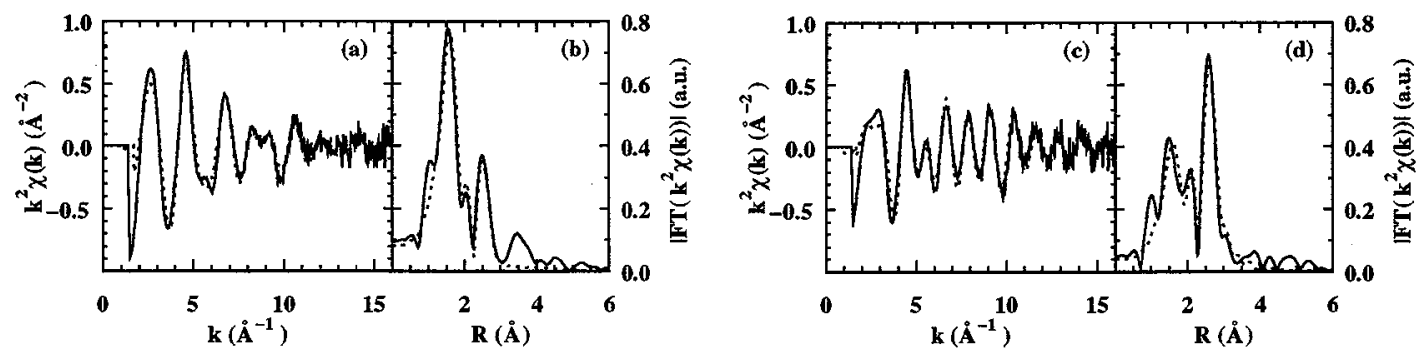

Figure 2: Pd XAFS spectra $k^{2} \chi(k)$ and corresponding FTs of membrane no. 2, before $(a, b)$ and after (c,d) reduction by $\mathrm{H}_{2}$ at $300 \mathrm{~K}$.

Table 1: Cluster sizes and surface oxide layer thicknesses determined from the XAFS analyses in comparison to the results of other techniques. XRD, TEM: numbers in brackets denote minority components. Metal loading is always $15 \mathrm{wt}$. $\%$.

\begin{tabular}{|l|c|c|c|c|c|c|}
\hline \multicolumn{1}{|c|}{ Membrane } & $\begin{array}{c}\text { XAFS: } \\
D / \AA\end{array}$ & $\begin{array}{c}\text { XAFS: } \\
l_{o x} / \AA\end{array}$ & $\begin{array}{c}\text { XAFS: } \\
N(P d-P d)\end{array}$ & $\begin{array}{c}\text { XAFS: } \\
N(P d-O)\end{array}$ & $\begin{array}{c}\text { XRD: } \\
L / \AA\end{array}$ & $\begin{array}{c}\text { TEM: } \\
D / \AA\end{array}$ \\
\hline 1 Pd, air, NMP, 1.5h & $24(10)$ & $4(1)$ & 2.8 & 2.5 & $12,(40)$ & $10-30,(200)$ \\
2 Pd, air, NMP, 3h & $14(4)$ & $3(1)$ & 1.3 & 2.8 & $9,(44)$ & $10,(140)$ \\
2 Pd, H, NMP, 3h & $13(2)$ & $1.5(3)$ & 3.7 & 1.4 & - & - \\
3 Pd, air, THF, 16h & $52(20)$ & $4(2)$ & 7.2 & 1.2 & 25 & $10-30$ \\
4 Pd/Ag(3:1), air, NMP, 3h & $17(4)$ & $3(1)$ & 2.2 & 2.5 & 15 & $20,(80)$ \\
4 Pd/Ag(3:1), H, NMP, 3h & $15(2)$ & $1.5(2)$ & 4.5 & 1.2 & - & - \\
\hline
\end{tabular}

the entire cluster ensemble and, therefore, should be transferred with care to microscopic pictures.

In Table 1 , the agreement of cluster sizes in the membranes determined by XAFS, XRD and TEM is convincing considering that the techniques do not probe identical properties and portions of the cluster ensemble. For example, the grain sizes $L$ measured by XRD correspond to the size of the metal cores of the clusters and therefore are expected to be systematically lower than the particle diameters determined by TEM and XAFS which include the surface oxide layers as well. From Table 1 it is seen that the solvent used in the preparation has a strong influence on the resulting cluster sizes. Since cluster sizes in membrane no. 3 are larger than in the other membranes, NMP, the better solvent for the polymer, is more favorable than THF. Independently, increasing the stirring time of the polymer/metal precursor solution from 1.5 (membrane no. 1) to 3 hours (membrane no. 2) improves the dispersion in the membrane since only solution of polymer chains and metal salt precursor on a molecular level yields minimum cluster sizes. Generally, no or weak indications of metal alloying in the bimetallic membranes are observed [6].

Figure 3 shows Pd XAFS spectra of Pd/Cu-loaded membranes of varying metal composition. From three-shell XAFS analyses it is observed that the additional peak in the FTs of Figs. $3 \mathrm{~b}, \mathrm{c}$ present at around $1.9 \AA$ in comparison to Pd-loaded membranes originates from $\mathrm{Pd}-\mathrm{Cl}$, i.e. is due to a reaction of chlorine from the $\mathrm{CuCl}_{2}$ precursor with $\mathrm{Pd}$ and not due to $\mathrm{Pd}-\mathrm{Cu}$ alloying. The determined bond length $R(P d-C l)=2.32(2) \AA$ is close to the one in $\mathrm{PdCl}_{2}$. This reaction may inhibit catalytic properties.

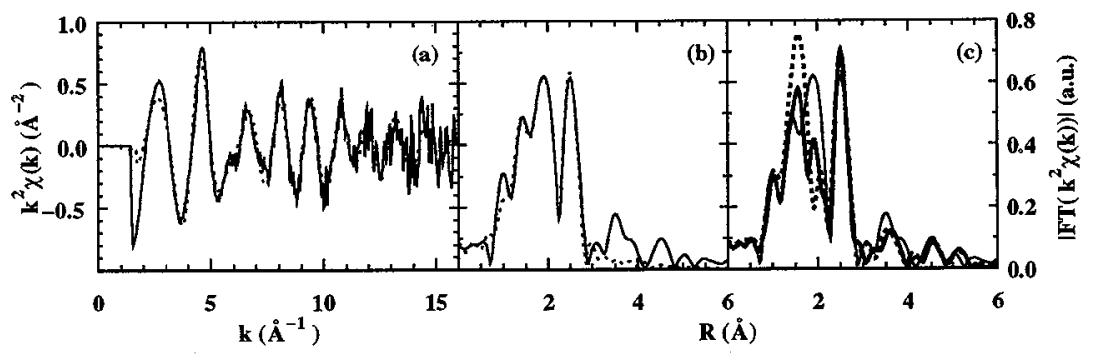

Figure 3: (a) Pd XAFS spectrum $k^{2} \chi(k)$ and (b) corresponding FT for a Pd/Cu(1:1)-loaded membrane; dotted lines: three-shell fits. (c) FTs for Pd/Cu-loaded membranes of composition (w/w) 1:1 (thin solid) and 9:1 (thick solid) in comparison to a pure Pd-loaded membrane (dotted).

\section{References}

[1] Fritsch D., Peinemann K.-V., J. Membrane Science 99 (1995) 29-38.

[2] Fritsch D., Peinemann K.-V., Catalysis Today 25 (1995) 277-283.

[3] Rehr J.J., Albers R.C. and Zabinsky S.I., Phys. Rev. Lett. 69 (1992) 3397-3400.

[4] Stern E.A., Newville M., Ravel B., Yacoby Y. and Haskel D., Physica B 208-209 (1995) 117-120.

[5] Fritsche H.-G., Benfield R.E., Suppl. Z. Phys. D 26 (1993) 15-17.

[6] Tröger L., Hünnefeld H., Nunes S., Oehring M., Fritsch D., submitted to J. Phys. Chem. 